\title{
COMMENTARY
}

\section{The key to advanced airways during cardiac arrest: well trained and early}

\author{
Peter T Morley* \\ See related research by Kajino et al., http://ccforum.com/content/15/5/R236
}

\begin{abstract}
Airway management during cardiac arrests is a controversial area. There are advantages to the provision of a patent airway with an airway adjunct, especially as this can optimize oxygenation and carbon dioxide clearance as well as facilitate continuous compressions. These advantages come at a potential cost, in particular errors in placement of the devices and interruption to compressions necessitated for insertion. The widespread availability of supraglottic airways (SGAs), their ease of insertion, and their ability to be inserted without interruptions to compressions have meant that the role of the definitive airway device - the endotracheal tube - is being challenged. In the previous issue of Critical Care, a study from Japan reported the use of advanced airways in more than 5,000 victims of cardiac arrests. The authors were not able to demonstrate a survival advantage with either SGAs or endotracheal intubation (ETI). They did, however, demonstrate improved outcomes when the emergency life-saving technicians had been trained to perform ETI and when the advanced airway device was inserted earlier.
\end{abstract}

One of the unanswered questions in cardiac arrest management is which approach to airway management is best: both the specific technique and the time to intervene. The International Liaison Committee on Resuscitation summarized this issue in its 2010 Consensus on Science document: 'There are no data to support the routine use of any specific approach to airway management during cardiac arrest. The best technique depends on the precise circumstances of the

*Correspondence: pmorley@unimelb.edu.au

University of Melbourne Clinical School, Royal Melbourne Hospital, Grattan Street, Parkville, Victoria, Australia 3050 cardiac arrest, local guidelines, training facilities, and the competence of the rescuer' [2].

Our understanding of this issue is taken one step further by an intriguing Japanese study that was published in the previous issue of Critical Care [1]. In this observational study from Osaka, 5,377 consecutive, witnessed, non-traumatic, out-of-hospital cardiac arrests (OHCAs) were treated with an advanced airway by emergency life-saving technicians (ELSTs) in the calendar years 2005 through 2008. The authors evaluated the time to advanced airway placement and the difference in outcomes between the use of endotracheal intubation (ETI) and the use of supraglottic airways (SGAs). The SGAs in use in Japan at the time of the study were the Combitube, the laryngeal mask airway (LMA), and the laryngeal tube.

The primary outcome measure of this study was neurologically favorable 1-month survival, defined as a cerebral performance category score of 1 or 2 . Favorable neurological outcomes were low (3.6\%) but similar between ETI and SGAs. Although the ETI group had a number of adverse prognostic features (2 years older, four times as many receiving epinephrine, and 1.4 minutes more to insert the airway), there were actually some statistically significant short-term survival benefits seen in this group: a greater proportion of pre-hospital return of spontaneous circulation (ROSC) (16.6\% versus $10.1 \%$ ) and an increase in ROSC in the emergency department (47.8\% versus $44.4 \%$ ).

During this study, CPR was performed according to the Japanese CPR guidelines, which initially were based on the 2000 American Heart Association (AHA) guidelines and which after October 2006 [3] were based on the 2005 AHA guidelines [4]. There was, unfortunately, no information about why the ELSTs chose a particular type of advanced airway device. By means of multivariable analysis, improvements in favorable neurological outcomes were demonstrated (irrespective of the airway device used) with the earlier insertion of the airway ( $9 \%$ decrease for every 1-minute delay) and the presence of an ELST who received the additional training required to be certified to use ETI. 
This association between improved outcome and the early placement of an advanced airway is consistent with recently published in-hospital cardiac arrest data in which the best short-term survival was seen in those patients in whom the advanced airway (including ETI or LMA) was placed within 5 minutes from collapse [5]. The observation that improved outcomes were seen with better-trained providers is also consistent with studies performed in the in-hospital setting [6,7].

As this study was not a randomized controlled trial, there may be unknown confounders. One word of caution about the interpretation of studies with unknown confounders is exemplified by an observational study from Australia [8]. In that study of OHCA, multivariate analysis demonstrated a threefold survival improvement associated with the use of ETI, and this was almost certainly due to the selection of patients more likely to survive [8].

Kajino and colleagues [1] rightfully point out that their study does not address whether an advanced airway is necessary at all during cardiac arrests. Earlier studies that were unable to find improved outcomes with the use of advanced airways $[9,10]$ may have had benefits outweighed by the adverse effects of ventilation, but a recent publication from Japan reported that the establishment of an SGA was actually a significant negative predictor of pre-hospital ROSC [11].

Unconscious patients requiring intensive care management after cardiac arrest will almost always require an advanced airway at some stage. It is still unclear whether the insertion of an advanced airway during cardiac arrest is necessary. If the decision to manage cardiac arrests by using advanced airways is made, a focus on increased training and earlier insertion seems beneficial.

\section{Abbreviations}

AHA, American Heart Association; ELST, emergency life-saving technician; ETI, endotracheal intubation; LMA, laryngeal mask airway; OHCA, out-of-hospital cardiac arrest; ROSC, return of spontaneous circulation; SGA, supraglottic airway.

\section{Competing interests}

The author declares that he has no competing interests.

Published: 11 January 2012

References

1. Kajino K, Iwami T, Kitamura T, Daya M, Ong ME, Nishiuchi T, Hayashi Y, Sakai T, Shimazu T, Hiraide A, Kishi M, Yamayoshi S: Comparison of supraglottic airway versus endotracheal intubation for the pre-hospital treatment of out-of-hospital cardiac arrest. Crit Care 2011, 15:R236.

2. Deakin CD, Morrison L, Morley PT, Callaway CW, Kerber RE, Kronick SL, Lavonas EJ, Link MS, Neumar RW, Otto CW, Parr M, Shuster M, Sunde K, Peberdy MA, Tang W, Hoek TL, Böttiger BW, Drajer S, Lim SH, Nolan JP; Advanced Life Support Chapter Collaborators: Part 8: Advanced life support: 2010 International Consensus on Cardiopulmonary Resuscitation and Emergency Cardiovascular Care Science with Treatment Recommendations. Resuscitation 2010, 81 (Suppl 1):e93-e174.

3. Japanese Guidelines for Emergency Care and Cardiopulmonary Resuscitation [in Japanese]. 3rd ed. Tokyo: Health Shuppansha; 2007.

4. ECC Committee, Subcommittees and Task Forces of the American Heart Association: 2005 American Heart Association Guidelines for Cardiopulmonary Resuscitation and Emergency Cardiovascular Care. Circulation 2005, 112 (24 Suppl):IV1-203.

5. Wong ML, Carey S, Mader TJ, Wang HE: Time to invasive airway placement and resuscitation outcomes after inhospital cardiopulmonary arrest. Resuscitation 2010, 81:182-186.

6. Moretti MA, Cesar LA, Nusbacher A, Kern KB, Timerman S, Ramires JA: Advanced cardiac life support training improves long-term survival from in-hospital cardiac arrest. Resuscitation 2007, 72:458-465.

7. Edelson DP, Litzinger B, Arora V, Walsh D, Kim S, Lauderdale DS, Vanden Hoek $\mathrm{TL}$, Becker LB, Abella BS: Improving in-hospital cardiac arrest process and outcomes with performance debriefing. Arch Intern Med 2008, 168:1063-1069.

8. Jennings PA, Cameron P, Walker T, Bernard S, Smith K: Out-of-hospital cardiac arrest in Victoria: rural and urban outcomes. Med J Aust 2006, 185:135-139.

9. Gausche M, Lewis RJ, Stratton SJ, Haynes BE, Gunter CS, Goodrich SM, Poore PD, McCollough MD, Henderson DP, Pratt FD, Seidel JS: Effect of out-ofhospital pediatric endotracheal intubation on survival and neurological outcome: a controlled clinical trial. JAMA 2000, 283:783-790.

10. Stiell IG, Wells GA, Field B, Spaite DW, Nesbitt LP, De Maio VJ, Nichol G, Cousineau D, Blackburn J, Munkley D, Luinstra-Toohey L, Campeau T, Dagnone E, Lyver M; Ontario Prehospital Advanced Life Support Study Group: Advanced cardiac life support in out-of-hospital cardiac arrest. NEng/ J Med 2004, 351:647-656.

11. Yanagawa Y, Sakamoto T: Analysis of prehospital care for cardiac arrest in an urban setting in Japan. J Emerg Med 2010, 38:340-345.

doi:10.1186/cc10552

Cite this article as: Morley PT: The key to advanced airways during cardiac arrest: well trained and early. Critical Care 2012, 16:104. 